\title{
Üniversite Öğrencilerinde Cep Telefonu Kullanımı İle Kimlik Gelişimi Arasındaki İlişki
}

Relationship Between Mobile Phone Usage and Identity Development in University Students

\author{
Gökçen AKYÜREK ${ }^{1}$, Sinem KARS ${ }^{2}$, Gonca BUMIN ${ }^{3}$ \\ ${ }^{1}$ Dr.Fzt., Hacettepe Üniversitesi Sağlık Bilimleri Fakültesi Ergoterapi Bölümü, Ankara \\ ${ }^{2}$ Uz. Erg., Hacettepe Üniversitesi Sağlık Bilimleri Fakültesi Ergoterapi Bölümü, Ankara \\ ${ }^{3}$ Prof. Dr., Hacettepe Üniversitesi Sağlık Bilimleri Fakültesi Ergoterapi Bölümü, Ankara
}

\section{öz}

\begin{abstract}
Amaç: Bu çalı̧manın amacı üniversite öğrencilerinde cep telefonu kullanımı ile kimlik gelişimi arasındaki ilişkinin incelenmesidir. Gereç ve Yöntem: Ergoterapi Bölümünde okuyan, çalışmaya katılmaya gönüllü olan 135 öğrenci (yaş ortalaması 20,9 2,67, \% 60,3'ü kadındı) çalışmaya alınmıştır. Çalışmada Kimlik Gelişiminin Boyutları Ölçeği ve Cep Telefonu Problemli Kullanım Ölçeği kullanılımıştır. Sonuçlar: Cep Telefonu Problemli Kullanım Ölçeğinin sosyal ilişki alt ölçeği ile Kimlik Gelişiminin Boyutları ölçeğinin içsel yatırımda bulunma, içsel yatıımla özdeşleşme ve seçeneklerin saplantılı araştırılması alt ölçekleri arasında bir ilişki bulunmuştur $(p<0,05)$. Kimlik Gelişiminin Boyutları ölçeğinin seçeneklerin derinlemesine araştırıması alt ölçeği ile Cep Telefonu Problemli Kullanım Ölçeğinin toplam puanı ile bağımlıık alt ölçeği arasında doğru orantııı anlamlı bir ilişki bulunmuştur $(p<0,05)$. Tartışma: Bulgulara göre, içsel yatıım yapabilme becerileri yüksek öğrenime giden öğrencilerin sosyal ilişkilerinin daha iyi olduğu görülmektedir. Kimlik gelişimi için seçeneklerini derinlemesine araştıramayan öğrencilerin telefona bağımlılı̆̆ ve telefonu problemli kullandıkları tespit edilmiştir. Böylece başarılı toplumunun temeli başarııı kimlik edinmiş genç nesiller yetiştirmekse bunun için önce örgün eğitimde gerekli girişimler sağlanmalı sonrada çağımızın sorunu olan cep telefonunun yanlış kullanımı ile ilgili gerekli düzenlemelerin toplumsal bazda yapılarak önüne geçilmesi sağlanmalıdır.
\end{abstract}

Anahtar Kelimeler: Bağımlıık; Sosyal kimlik; Servisler; Toplum sağlığı; Eğitim

\section{ABSTRACT}

Purpose: The aim of this study is to examine the relationship between mobile phone use and identity development in university students. Material and Methods: 135 volunteers who wanted to voluntarily participate (average age $20.9 \pm 2.67,60.3 \%$ female) were included in the study. The Dimensions of Identity Development Scale and Problematic Mobile Phone Use Scale were used in the study. Results: There was found a relationship between the score of the Social Relationship subscale of the Problematic Mobile Phone Use Scale and commitment making ( $r=-0.227, p=0.008)$, identification with commitment $(r=-0.197, p=0.022)$ and ruminative exploration subscales $(r=0.174, p=0.043)$ of The Dimensions of Identity Development Scale. There was found a relationship between the exploration in depth subscale of The Dimensions of Identity Development Scale and the total score $(r=0.238, p=0.005)$ and dependency subscale $(r=0.292, p=0.001)$ of the Problematic Mobile Phone Use Scale. Conclusion: According to the findings, it can be seen that the university students who have the ability of commitment making are better in social relations. It has been determined that the students who cannot explore their options in identity development have problematic and dependent telephone use. Moreover, if the aim of a successful society is to bring up young generations who have adopted successful identities, first of all, the necessary interventions should be done in formal education and later on, the necessary arrangements to prevent the wrong usage of mobile phones should be done in the society.

Key Words: : Dependency; Social identity; Services, Community health; Education

Sorumlu Yazar (Corresponding Author): Gökçen AKYÜREK E-mail: gkcnakyrk@gmail.com

ORCID ID: 0000-0002-0309-2321

Geliş Tarihi (Received): 01.08.2018; Kabul Tarihi (Accepted): 06.03.2019

Bu araştırmanın özeti 02-05 Mayıs 2018 tarihinde $\mathrm{V}^{\text {th }}$ International Euroasian Educational Research Congress'te sözel bildiri olarak sunulmuştur. 
Üniversite yılları kimlik gelişimi için bireyin çaba gösterdiği yıllardır. Bu dönemde yaşanan kimlik yapılandırmaları sırasında ergenlerin ne tür davranışlar ortaya koydukları birey ve toplum için oldukça önemlidir. Erikson'a göre birey, ergenliğe girmesi ile çocukluk dönemine benzer bir büyüme yaşadığı için, ergenlikten önceki durumlarını sorgular. Büyüyerek değişen ergenler yeni hallerinin diğerlerinin gözünde nasıl olduğunu bilmek isterler (Erikson, 1984; Kroger, 2004). Bu dönemde roller ve alışkanlıklar kimlik gelişimi ile şekillenmektedir. Bu durum, onlara göre oldukça büyük bir çaba gerektirir. Erikson'un Psikososyal Gelişim Kuramı, kimlik gelişimini en iyi açıklayan teoridir. Erikson (1994) kimliği, "bireyin biricikliğinin bilinçli duygusu; deneyimlerin sürekliliği için bilinçsizce çaba ve grubun düşünceleri ile dayanışma" olarak tanımlamaktadır.

Marcia ise kimliği, benliğin yapılandırılması olarak tanımlamış ve seçeneklerin araştıııması ve içsel yatırım olarak statüler belirlemiştir. Buna göre, başarılı kimlik statüsünde yer alan bireyler, olası seçenekleri etkin bir şekilde araştırarak içsel yatırımlarda bulunur. Marcia (2002) ve Kroger'e (Kroger, 2002a; Kroger, 2002b; Kroger, Marcia, Whitbourne ve ark., 2002) göre ergenliğin kimlik gelişiminde doruk noktası olmasının nedeni ergenliğin fiziksel, bilişsel, ahlaki ve cinsel gelişim ve değişimlerinin en hızlı biçimde yaşandığı dönem olmasıdır. Marcia'ya (2002) göre, toplumun, ergenin rollerini giyinmesi, denemesi ve sürdürmesini beklediğinden bu dönemde kimlik gelişimi doruk noktasına ulaşır. Ancak gelişen ve değişen teknoloji ile gençlerin yaşamları, rolleri ve alışkanlıkları farklılaşmış ve farklılaşmaya da devam etmektedir. Başlangıçta sadece iletişim aracı olarak kullanılan telefonlar, günümüzde birçok işlevi ile bu özelliğinin ötesine geçmiş, hayatımızın ayrımaz bir parçası olmuştur (Karaaslan ve Budak, 2012). Yaşamı kolaylaştırma özelliğine sahip bu aygıtlara olan talep ve atfedilen değeri artmış; geçmişte sabit olarak kablolara bağııı̆̆ı nedeni ile sınırlı olarak kullanılan telefonlar, işlevleri ve mobil olmaları nedeni ile alışkanlık/ asistan / oyun arkadaşı vb. olmuş, internetin imkânları ile hayatımızda önemli bir yer edinmeyi başarmıştır. Araştırmalarda toplumun yeni statü göstergesi olarak gösterilen (Marwick, 2008) akıllı telefonların aşırı kullanımının en önemli nedenlerinden biri sosyal platformlara ve internete sürekli bağlantıda kalabilmeyi sağlaması nedeniyle bireylerde yalnızlık endişelerini azalttığı görülmektedir (Townsend, 2000). Üniversite öğrencilerinde yapılan bir araştırmada akıllı telefon kullanım sıklığının çok yüksek olduğu ve 20 yaş ve altı bireylerin bağımlılık düzeylerinin diğer yaş gruplarına göre daha yüksek olduğu öğrencilerin bağımlılık düzeylerinin artması sonucunda da sözel iletişimleri ile sosyal yaşamlarını negatif yönde etkilemekte olduğu ve eğitimlerini zorlaştırdığı sonucuna ulaşılmıştır (Kahyaoğlu-Süt, Kurt, Uzal ve ark., 2016). Diğer bir araştırma akıllı telefon bağımlılık ile narsisizm, nevrotiklik ve yaş değişkeninin bağlantılı olduğunu ortaya koymuştur (Pearson ve Hussain, 2016). Soni, Upadhyay ve Jain (2017) akıllı telefonların kullanımı arttıkça uyku ve davranış sorunları geliştirdikleri sonucuna varmıştır. Ayrıca, cep telefonlarının yüz yüze iletişim ve ilişkiler ile bireysel planlama ve zamanlama yapılarını olumsuz etkilediğini göstermişlerdir. Bunun yalnızlık ve akademik başarısızlığı da beraberinde getirdiğini göstermişlerdir (Thulin ve Vilhelmson, 2007). Kullanımının ve işlevlerinin giderek artması nedeni ile araştırmalara konu olan bu işlevsel (akıllı) telefonların sağlığımız üzerine etkileri (fiziksel ve psikolojik sağlık, kişilerarası ilişkiler gibi konular üzerinde olumsuz etkileri) olduğu literatürde ortaya konulmuştur. Ancak kimlik gelişiminin hızlı olduğu bu zaman dilimindeki etkisi ile ilgili bir bilgiye rastlanmamıştır. Bu nedenle bu çalışmanın amacı üniversite öğrencilerinde cep telefonu problemli kullanımının kimlik gelişimi ile ilişkini incelemektir.

\section{GEREÇ VE YÖNTEM}

$\mathrm{Bu}$ araştırma ilişkisel tarama yöntemine göre dizayn edildi. Araştırmanın örneklemini 2017-2018 öğretim yılı güz ve bahar döneminde Hacettepe Üniversitesi Sağlık Bilimleri Fakültesi Ergoterapi Bölümünde okuyan, çalışmaya katılmaya gönüllü olan 135 öğrenci oluşturmaktadır. Çalışmanın etik kurulu; Hacettepe Üniversitesi Senato Etik Komisyonu'ndan çalışmanın yapılmasında etik açıdan sakınca olmadığına ilişkin izin alındı. Çalışma öncesi tüm katıımcılar çalışma ile ilgili bilgilendirildi ve gönüllü katııım formu imzalatıldı.

Öğrenciler veri toplama araçlarını sınıflarında doldurmuşlardır. Öğrencilerin yaş aralığı 17-25'dir. Araştırma kapsamındaki üniversite öğrencilerinin yaş ortalaması $20,9 \pm 2,67$ olup, $\% 60,3$ 'ü kadındı (Tablo 1 ). Katılımcıların \%100'ü akıllı telefon kullanıcısı idi. 
Tablo 1. Demografik bilgiler

\begin{tabular}{llll}
\hline & \multicolumn{2}{l}{ Toplam } \\
\hline Cinsiyet & & $\mathrm{n}$ & $\%$ \\
& Erkek & 53 & 39,7 \\
\hline Üniversitedeki yılı & Kadın & 82 & 60,3 \\
& 1 & 25 & 16,6 \\
& 2 & 32 & 31,8 \\
& 3 & 41 & 25,4 \\
\hline Toplam & 4 & 37 & 28,0 \\
& & 135 & 100
\end{tabular}

Çalışmamıza dahil etme kriterleri; Hacettepe Üniversitesi Sağlık Bilimleri Fakültesi Ergoterapi Bölümünde 2017-2018 öğretim yılı güz ve bahar döneminde öğrenim görmek, onam formunu imzalamış olmak ve Türk dilini okuyup anlıyor olmaktır.

Çalışmada Kimlik Gelişiminin Boyutları Ölçeği ve Cep Telefonu Problemli Kullanım Ölçeği kullanılmıştır.

Kimlik Gelişiminin Boyutları Ölçeği (KGBÖ).

Kimlik gelişimi boyutları ölçeği Luyckx ve arkadaşları tarafından geliştirilmiş, Morsünbül tarafından Türkçeye uyarlanmıştır (Luyckx, Schwartz, Berzonsky ve ark., 2008; Morsünbül, 2011). Bu ölçek, seçeneklerin genişlemesine araştırılmasını (exploration in breadth); seçeneklerin derinlemesine araştırımasını (exploration in depth); seçeneklerin saplantılı araştırılmasını (ruminative exploration); içsel yatırımda bulunmayı (commitment making); içsel yatırımla özdeşleşmeyi (identification with commitment) olmak üzere beş alt boyuta sahiptir. Her alt boyut 5'er madde ile ölçülmektedir. Maddeler doğru sıralanan 5'li Likert (kesinlikle katılıyorum=5, kesinlikle katılmıyorum=1) şeklinde puanlanmaktadır. Ölçeğin her alt boyutu ayrı ayrı değerlendirilmekte ve alt ölçeklerin alacağı puanları 5 ila 25 arasında değişmektedir. Ölçeğin Türkçe versiyonunun alt boyutlar için Cronbach alfa değerleri 0,79-0,86 arasında değişmektedir (Morsünbül, 2011).

Cep Telefonu Problemli Kullanım Ölçeği (CTPKÖ) Augner ve Hacker tarafından geliştirilmiş Tekin tarafından Türkçeye uyarlanmıştır. (Augner ve Hacker, 2012; Tekin, Gunes ve Colak, 2014). Ölçek cep telefonu aşırı kullanımı ile oluşabilecek problemleri ve bazı psikolojik değişkenlerin ilişkisini ölçmek amacıyla Almanca olarak geliştirilmiştir. Ölçek 26 sorudan 3 alt boyuttan oluşmaktadır. Bunlar, bağımlılık, sosyal ilişkiler, sonuçlar'dır. Bağımlılık ve sosyal ilişkiler bölümünde yer alan her bir madde 0-4 puan $(0=$ kesinlikle katılmıyorum, 4=kesinlikle katılıyorum), Sonuçlar bölümünde yer alan her bir madde ise 0 (hiç) -4 (çok sık) puan Likert skalası aracılığı ile puanlandırılmaktadır. Toplam puan yüksekse, bu, kişinin cep telefonunu problemli kullandığını göstermektedir (Tekin, Gunes ve Colak, 2014).

Istatistiksel Analiz

Verilerin istatistiksel analizlerinde SPSS 23,00 paket programı kullanılmıştır. Ölçümle belirlenen değişkenler, ortalama ve standart sapma $(X \pm S S)$ olarak ifade edilmiş, sayımla belirlenen değişkenler için yüzde (\%) değeri hesaplanmıştır. Ölçeklerin alt parametreleri arasındaki ilişki parametrik test koşulları sağlanamadığından dolayı Spearman korelasyon analizi ile incelenmiştir. Tüm istatistiklerde $p$ anlamlılık değeri 0,05 olarak alınmıştır.

\section{SONUÇLAR}

Çalışmamıza katılan öğrencileri \%39,7'si erkek ve yaş ortalamaları 21,1'di. Ölçeklerin ortalama ve standart sapmaları hesaplanmıştır (Tablo 2). Cep Telefonu Problemli Kullanım Ölçeğinin sosyal ilişkiler alt ölçeği ile Kimlik Gelişiminin Boyutları ölçeğinin içsel yatırımda bulunma $(r=-0,227, p=0,008)$ ve içsel yatırımla özdeşleşme $(r=-0,197, p=0,022)$ alt ölçekleri arasında ters; seçeneklerin saplantılı araştırılması ( $r=0,174$, $p=0,043$ ) alt ölçeği arasında doğru orantılı bir ilişki bulunmuştur. Kimlik Gelişiminin Boyutları ölçeğinin seçeneklerin derinlemesine araştırılması alt ölçeği ile Cep Telefonu Problemli Kullanım Ölçeğinin toplam puanı $(r=0,238, p=0,005)$ ile bağımlılık $(r=0,292$, $p=0,001$ ) alt ölçeği ise doğru orantılı anlamlı bir ilişki bulunmuştur (Tablo 3 ). 
Tablo 2. Ölçeklerin ortalama ve standart sapma değerleri

\begin{tabular}{llll}
\hline & (n=135) & Ortalama (SS) & Min-Max \\
\hline Kimlik Gelişiminin Boyutları Ölçeği & SDA & $19,21(2,96)$ & $9-25$ \\
(KGBÖ) & SSA & $15,59(4,66)$ & $4-24$ \\
& SGA & $20,04(2,55)$ & $14-25$ \\
& IYB & $19,26(2,96)$ & $11-25$ \\
& IYÖ & $18,47(3,36)$ & $9-25$ \\
& TOPLAM & $42,41(13,82)$ & $6-76$ \\
\hline Cep Telefonu Problemli Kullanım & Sosyal ilişki & $9,41(3,36)$ & $2-18$ \\
Ölçeği (CTPKÖ) & Bağımlıık & $12,41(5,72)$ & $0-24$ \\
& Sonuç & $10,45(5,66)$ & $0-30$
\end{tabular}

SS: standart sapma; Min-Max: minimum ve maksimum değerler; SDA: seçeneklerin derinlemesine araştırıması; SSA: seçeneklerin saplantılı araştırılması; IYB: içsel yatırımda bulunma; IYÖ: içsel yatırımla özdeşleşme

Tablo 3. Cep telefonu kullanımı ile kimlik gelişimi arasındaki ilişkiyi gösteren korelasyon sonuçları

\begin{tabular}{llll}
\hline & Sosyal ilişkiler & Bağımlılık & Toplam \\
\hline SDA & & $0,292^{*}$ & $0,238^{*}$ \\
SSA & $0,174^{*}$ & & \\
IYB & $-0,227^{*}$ & & \\
IYÖ & $-0,197^{*}$ & & \\
\hline
\end{tabular}

${ }^{*} \mathrm{p}<0,01$; SDA: seçeneklerin derinlemesine araştırılması; SSA: seçeneklerin saplantılı araştııılması; iYB: içsel yatırımda bulunma; IYÖ: içsel yatırımla özdeşleşme

\section{TARTIŞMA}

Üniversite öğrencilerinde cep telefonu kullanımı ile kimlik gelişimi arasındaki ilişkinin incelemeyi amaçlayan bu çalışmaya göre kimlik gelişim ile cep telefonunun problemli kullanımı arasında anlamlı bir ilişki vardır.

Kimlik gelişimi ile ilgili bir çok kuram literatürde var olmasına rağmen Marcia'nın kimlik statüleri (Marcia, 2002) kuramı, kimlik gelişim statüleri kavramını önermesi ve kimlik konusuna yeni bir bakış açısı getirmesi ile önemli bir yere sahiptir. Marcia kimlik ile ilgili, duyum (sense), tutum (attitude) ve çözüm (resolution) kavramlarını kullanır ancak "içsel bir kendilik yapılanması" (internal self constructed) teriminin kimliği daha iyi açıkladığını savunur. Bireyin dürtüleri, yetenekleri, inançları ve bireysel tarihinin örgütlenmesi ile kimlik meydana gelir (Marcia, 2002) Marcia, Erikson'un kimlik ile ilgili ikilemini incelemiş ve dört kimlik statüsünü "araştırma" ve "karar verme" düzeyine göre belirlemiştir. Marcia'ya göre, ego kimliğinin oluşmasında iş ve eş seçimi gibi kritik kimlik olaylarında güçlü bir adanmışlık/içsel yatırım (commitment) gerekmektedir (Marcia, 2002). Yani irdeleme, sorgulama ve karar verme süreçleri ile kimlik oluşturmada temel etkenlerdir. Araştırma boyutunda, ergen, seçeneklerini tanımaya ve sorularına yanıtlar aramaya çalışır. Karar boyutunda ise davranışı yönlendirmelidir ve bu bir tercihtir. Ergenlik döneminde, ideoloji ve kişilerarası seçenekleri araştırma ve karar verme kimlik gelişimine katkı sağlamaktadır. Dini inanışlar, politik seçimler, meslek seçimi, felsefi yaşam biçimi ise ideolojik alanı oluştururken; arkadaşlık, flört, cinsiyet rolü ve serbest zaman aktiviteleri ise kişilerarası alanı oluşturur (Marcia, 2002).

Çağımızda cep telefonu, artık sadece uzaktan iletişim aracı olarak kullanılmamaktadır. Hatta cep telefonu, internet bağlantısı ve birçok programın kullanılabilirliği ile bir bilgisayarın tüm özelliklerini göstermektedir. Kullanıcılara fotoğraf ve video çekimi, mesajlaşmanın yanı sıra mekân sınırlaması olmadan WEB'de gezinme, çok oyunculu oyunları oynayabilme, video izleme ve sosyal medyayı kullanma gibi imkânlar sağlaması nedeni ile sadece telefon modeli/türüne (akıllı telefon) geçiş hızlanmadı, bunun yanı sıra cep 
telefonu önemli bir serbest zaman aracı olarak kullanımının artmasına da neden oldu (Lepp, 2014). Bu da, özellikle teknoloji yerlisi olarak adlandırılan gençlerde yaygın biçimde kullanılmasına ve kullanımın bağımlılık seviyesine gelmesine neden oldu. Ergenlerde telefon kullanımı bağlılığı telefonların artan fonksiyonlarından bağımlılığı ise sosyal medya ve aplikasyonlar ile çeşitli programları çalıştırma özelliklerinden kaynaklanmaktadır (Fırat ve Çelik, 2017).

Kimlik oluşturma süreci, yaşam olayları ve seçimleri içermektedir (Arnett, 2004). Özellikle meslek ve dünyaya bakış açısı ile ilgili deneme ve karar verme süreçleri ergenlikte başlar ve üniversite döneminde netlik kazanır.

Araştırmada öğrencilerin kimlik gelişimi ile ilgili Marcia'ya göre içsel yatırımda bulunma ve bu yatırımla özdeşleşme puanı (adanma/bağlanma) yükseldikçe kişinin sosyal ilişkilerinin arttığını görülmektedir. Yaptığımız çalışmanın sonuçlarına bakıldığında da içsel yatırım yapabilme becerileri yüksek öğrencilerin sosyal ilişkilerinde problem olmadığı yani sosyal daha iyi olması nedeniyle literatürle sonuçlarımız tutarlılık göstermektedir. Ayrıca literatür içsel yatırım yapabilme ile ilgili, başarılı kimlik statüsünü yani, kimlik çatışmasını başarıyla çözümlemiş ve kendileri ile uyum içinde, kendi kapasitelerini, sınırlılıklarını ve düşüncelerini kabul eden bireyleri kast etmektedir. Bu bireyler, diğer statülere oranla çok daha başarılı ve yaratıcı davranışlar sergilemekle birlikte, mantıklı, akılcı ve planlı karar verme stratejilerini çok daha iyi kullanmaktadırlar (Marcia, 2002).

Araştırmamızın bir diğer önemli sonucu olarak, kimlik gelişimi için seçeneklerini derinlemesine araştıran öğrencilerin telefona bağımlılı̆ı ve telefonu problemli kullandıkları tespit edilmiştir. Literatür bu sonucu da destekler nitelikte olup, seçeneklerini derinlemesine araştıran kişilerin kimlik alanlarına henüz keşif yaptığını ve herhangi bir adanmışlık/bağlanmada bulunamadıklarını ya da yanlış bağlandıklarını göstermektedir. Bu bireyler, çeşitli seçenekleri irdelemiş olsalar bile henüz belirli bir yönelimleri oluşmamıştır. Öz saygı ve özerklik düzeyinin düşük olması nedeni ile yanlış davranışlar (alkol/sigara kullanımı gibi) ile kaçış davranışlarına yönelebildiklerini bunun da sosyal becerilerini olumsuz etkilediğini belirtmektedir (Marcia ve Kroger, 1993). Literatüre göre seçeneklerin araştırılması başarılı bir kimlik oluşturma için ön koşul olsa da, bu bireyler henüz hangi hedeflerin peşinden gideceğine dair kararlarını vermemişlerdir. Bu kararı vermeleri ile, onlar başarılı, yaratıcı, mantıklı ve akılcı karar verme stratejilerini kullanabilir ve güvenli bağlanmalar gerçekleştirebilirler. Bu da, onların sosyal becerilerini artırarak doğru ilişkiler kurmalarına neden olabilir (Arnett, 2004).

Sonuç olarak, seçeneklerin doğru şekilde araştırılması ve içsel yatırım süreçlerinin doğru işlemesi cep telefonunun problemli kullanımını azaltarak özellikle bağımlılık ve sosyalleşme üzerinde etkilidir.

Çalışmamızın bazı limitasyonları vardır. Araştırmanın sağlıklı popülasyonda yapılması nedeni ile korelasyon katsayıları oldukça düşük çıkmıştır. Bu nedenle gelecekte yapılacak araştırmalarda, cep telefonu problemli kullanımı bir klinikte doğrulanmış bireylerin kimlik statüleri daha ayrıntılı incelenebilir. Ayrıca, bu araştırmaların aynı bireylerde ergenlik ve yetişkinlik dönemlerini karşılaştıran takip çalışmaları şeklinde planlanması ile kimlik gelişimi daha ayrıntılı incelenebilir.

Böylece başarılı toplumunun temeli başarılı kimlik edinmiş genç nesiller yetiştirmekse bunun için önce örgün eğitimde gerekli girişimler sağlanmalı sonrada bu konu ile ilgili gerekli düzenlemelerin toplumsal bazda eğitimciler tarafından yapılarak çağımızın sorunu olan cep telefonunun yanlış kullanımının önüne geçilmesi sağlanmalıdır.

\section{Kaynaklar}

Arnett, J. J. (2004). Emerging adulthood: The winding road from the late teens through the twenties. New York: Oxford Press.

Augner, C., \& Hacker, G. W. (2012). Associations between problematic mobile phone use and psychological parameters in young adults. Int J Public Health, 57(2), 437-441.

Erikson, E. H. (1994). Identity: Youth and crisis (No. 7). WW Norton \& Company.

Erikson, E. H. (1984). İnsanın Sekiz Çağı, (Çev. TB Üstün, V Şar). Birey ve Toplum Yayıncılık, Ankara.

Fırat, N., \& Çelik, S. B. (2017). Cep Telefonu Bağımlılığı Ölçeği (CBÖ)'nin Türkçe'ye uyarlanması: Geçerlik ve güvenirlik çalışması. Int J Human Sci, 14(3), 2875-2887.

Kahyaoğlu-Süt, H., Kurt, S., Uzal, Ö., Özdilek, S. (2016). Sağlık bilimleri fakültesi öğrencilerinin akıllı telefon bağımlılık düzeylerinin sosyal ve eğitim hayatına etkisi. Avrasya Aile Hekimliği Dergisi, 5(1), 13-19.

Karaaslan, İ. A., \& Budak, L. (2012). Üniversite öğrencilerinin cep telefonu özelliklerini kullanımlarının ve gündelik iletişimlerine etkisinin araştırılması. Journal of Yasar University, 7(26).

Kroger, J. (2004). Identity in adolescence: The balance between self and other. Psychology Press, Routkedge, New York.

Kroger, J. (2002a). Introduction: Identitiy development through 
adulthood. Identity: An International Journal of Theory and Research, 2, (1), 1-5.

Kroger, J. (2002b). Identity processes and contents through the years of late adulthood. Identity: An International Journal of Theory and Research, 2 (1), 81-99.

Kroger, J., Marcia, J. E., Whitbourne, S. K., Sneed, J. R., Skultety, K. M., Strayer, J., Kroger, J. \& Raskin, P. M. (2002). Afterword. Identity: An International Journal of Theory and Research, 2(1), 109-113.

Lepp, A. (2014). Exploring the relationship between cell phone use and leisure: an empirical analysis and implications for management. Managing Leisure, 19(6), 381-389.

Luyckx, K., Schwartz, S. J., Berzonsky, M. D., Soenens, B., Vansteenkiste, M., Smits, I., \& Goossens, L. (2008). Capturing ruminative exploration: Extending the fourdimensional model of identity formation in late adolescence. J Res Pers, 42(1), 58-82.

Marcia, J. E., \& Kroger, J. (1993). The relational roots of identity. Discussions on Ego Identity, Psychology Press, Routkedge, New York.

Marcia, J. E. (2002). Adolescence, identity, and the Bernardone family. Identity: An International Journal of Theory and Research, 2(3), 199-209.

Marwick, A. E. (2008). Becoming Elite: Social status in Web 2.0 Cultures. New York.

Morsünbül, Ü. (2011). Ergenlikte özerkliğin ve kimlik biçimlenmesinin öznel iyi oluş üzerindeki etkisi (Yayımlanmamış Doktora Tezi). Ankara Üniversitesi, Ankara.

Pearson, C., \& Hussain, Z. (2016). Smartphone addiction and associated psychological factors. Addicta: The Turkish Journal on Addictions, 3, 193-207.

Soni, R., Upadhyay, R., \& Jain, M. (2017). Prevalence of smart phone addiction, sleep quality and associated behaviour problems in adolescents. Int $\mathrm{J}$ Res Med Sci, 5(2), 515-519.

Tekin, C., Gunes, G., \& Colak, C. (2014). Cep Telefonu Problemli Kullanım (PU) Ölçeğinin Türkçe'ye Uyarlanması: Geçerlik ve Güvenilirlik Çalışması. Med Science 3(3), 1361-81.

Thulin, E., \& Vilhelmson, B. (2007). Mobiles everywhere: Youth, the mobile phone, and changes in everyday practice. Young, 15(3), 235-253.

Townsend, A. M. (2000). Life in the real-time city: Mobile telephones and urban metabolism. Journal of Urban Technology, 7(2), 85-104. 